\title{
Strategies about Compiling of Mandarin Textbooks in Colleges and Universities
}

\author{
F. SUN \\ School of Political Science and Law, Shandong Institute of Business and Technology, Shandong, China
}

\begin{abstract}
This paper, having examined the popular mandarin training materials, analyzes the defects of the existing mandarin textbooks, combined with evaluation principle of language training materials and the author's own teaching experience, provides some strategies and suggestions for current compiling of mandarin textbooks, which involve macro of material and the basic unit, also involves the part of the teaching details.
\end{abstract}

KEYWORDS: Mandarin; Textbooks Compiling; Strategies

\section{INTRODUCTION}

Since the Outline of Putonghua Proficiency Test promulgated by the State in 1994, Mandarin popularization has become a trend throughout the country. Many college and university students, in addition to the announcer and teachers whose occupation requires PSC, have started to participate in the test. Consequently, various versions of Mandarin textbooks by colleges and universities were written to meet all the needs of Putonghua teaching and self-study. This paper summarizes the current system and the characteristics of the Mandarin textbooks, combined with evaluation principle of language training materials and the author's own teaching experience, trying to find some problems with the Mandarin textbooks, and giving the correspondingly reasonable proposals and strategies.

\section{PRESENT SITUATION OF THE COLLEGE AND UNIVERSITY MANDARIN TEXTBOOKS IN RECENT YEARS}

\subsection{The situation of Mandarin textbooks}

The promotion of Mandarin nationwide was written into the Constitution in the 1980s. With the development of society, economy, culture, more and more people began to use Mandarin. In 1994 three National Ministries issued Decision on the Test of Mandarin Proficiency, which triggered off a wave of Mandarin textbooks compiling for Mandarin proficiency test and Mandarin improvement. By the end of 2013, there have emerged more than several hundred books in which "Putonghua" can be found. These books can be classified into different types. In terms of compiling, they can be divided into two types: examination-oriented and improvement-oriented; in terms of applicable region: universal and regional; in terms of resulting effect: phonetic and oral.

\subsubsection{The textbooks are mostly exam-oriented}

Because the Mandarin classes in universities and colleges are often set for PSC, most textbooks are based on and guided by the Outline of Putonghua Proficiency Test and the Implementation Outline for Putonghua Proficiency Test, which means a high level of concord between the textbooks and the PSC content. Therefore, these textbooks, which includes two parts: basic Mandarin theory and training and instruction for PSC, are written in the following way: theory first, then exercises, and finally the test. There still are a few books which focus on the improvement of Mandarin proficiency. These books, however, have something to do with oral Mandarin, speech, broadcast, etc. Thus, these books lay more emphasis on sentence organization, discourse organization and sound training except phonetics.

\subsubsection{Applied to different regions}

Because of test purpose, according to the Implementation Outline for Putonghua Proficiency Test, local language offices, following the characteristics of local dialects, compiled textbooks targeted at local students. At present basically each province or autonomous region has its own Mandarin teaching materials, which provides sound identification and exercises according to their 
respective local dialects. But there are also textbooks suitable for students in colleges and universities nationwide. Exercises of sound identification and mistakes correction in these books are based on the characteristics of local dialects.

\subsubsection{Different emphasis}

As most textbooks are aimed at helping students to pass the PSC, naturally the emphasis is laid on the language - the Mandarin, especially on the Mandarin correction of pronunciation, vocabulary and grammar mistakes, and on intensive training exercises. But we are learning Mandarin not just for passing the PSC, but to put it into practice and use it as a tool and as a skill. Therefore, there are still Mandarin textbooks which focus on exercises of Mandarin and training of oral Mandarin, speech and broadcast, ensuring professional qualities for tour guides, teachers, civil servants, and the announcers.

\subsection{Characteristics of mandarin textbooks compiling}

\subsubsection{Compiling basis: the Outline as the instruction}

Most Mandarin textbooks in colleges and universities take the Outline of Putonghua Proficiency Test as a guide to build the structure of the entire book. Four compulsory parts are well structured with rich common characters and sentences exercises, reading exercises and topic talking exercises, thus ensuring progress from sound and intonation to characters and sentences, to reading and grasping of the discourse and finally to progress in daily oral Mandarin.

\subsubsection{Compiling sequence: sound, rhyme, tones, reading, and talking}

In most textbooks, explanations to sound, rhyme and tones are usually arranged first, following the sequence of sound, rhyme and, with an aim to improve practice by theory and finally to understand the discourse. Of course there are a small number of books which are not following the above sequence but the tones, sound, and rhyme order. These books hope to help students make progress in syllables as a whole.

\subsubsection{Compiling priority: emphasis on phonetics}

Currently emphasis is laid on Mandarin pronunciation teaching, with the basic knowledge of Mandarin phonetics, such as sound, rhyme, tone, sound change theory and vocal training as the focus. Attention is generally diverted to evaluation of standard phonetics in reading and talking exercises. Some people think that, in addition to phonetics, vocabulary and grammar, even conversation skills should also be paid attention to. Some Mandarin textbooks in the south pay attention to vocabulary and grammar, while in textbooks in the north no attention is paid to vocabulary and grammar due to a resemblance in words and grammar between dialects in the north and Mandarin.

\section{PROBLEMS WITH UNIVERSITY MANDARIN TEXTBOOKS}

\subsection{Boring theory explaining}

Most universities Mandarin textbooks are not suitable for teaching and self-studying because of lack of clear structure and teaching idea, which is an inevitable result of the fact that most textbooks are based on the Outline of Putonghua Proficiency Test. Pure theory teaching is more suitable for language major students than for the common non-majors, who are the readers of the textbooks. Therefore, textbooks compilers should reflect on how to make theory explanation attractive to students and how to correct and improve their pronunciation. Experience can be drawn from FLTSL (foreign language teaching as a second language) to make the textbooks more interesting and attractive to students disseminated in the network information.

\subsection{Focus on phoneme makes sentences ignored by learners}

The teaching aim current most textbooks is the correction of pronunciation errors and defects, which usually means that a syllable is divided into three parts and exercises are aimed at the three parts. Of the same drills, focus is not laid on the difficulty of syllable combination, but only on the extensive phoneme substitution. Attention is not paid to syllable practice in sentences and not to phonemes substitution of similar syllables in sentences, which means neglect of subtle difference in pronunciation in language flow.

\subsection{Lack of the grasp of the rules of language learning}

The linear arrangement of the teaching materials from phonetic to reading and to talking (oral) makes it easy for the teacher to grasp the overall thought pattern in teaching, while it also means a lack of in-depth research on language learning characteristics. In theory, syllable practice clears the obstacles in discourse reading. In reality, however, the adjacent syllables will influence each in language flow, which makes it difficult for the drills pattern from syllables to sentences or discourses realized. The "word - phrase -sentence" structure like a layered device does not exist in reality. At the same time, over the past ten years, many scholars have realized the influence of the tone on the syllables, such as Wang Qunsheng (1995), Xing 
Hanguo (2008), Sun Fei (2011). They have tried the drills pattern of tone training before consonant and vowel training, but most current textbooks are written according to consonant-vowel-tone pattern.

\subsection{Lack of the level of distinction between the different students}

Since the candidates are classified into six categories of three levels by the PSC, it means that the students in the acceptance of Putonghua training when the level is uneven. Therefore, let the students of different levels of the same exercise, not only a waste of students with high level of energy and time, hit the enthusiasm of their learning, so they can't see their own problems, could not see the improve direction, at the same time afford not to their own problems effect on those students with low level, can't do fine analysis on one of their defects. Exercises in some materials such as Putonghua Training and Testing Guide (Yunnan Language Work Committee Group), Putonghua Testing Tutorial (Guangdong Language Training and Testing Work Office) are classified into three levels: primary, intermediate and advanced.

\section{BASIC PRINCIPLES OF CLASSROOM TEACHING OF MANDARIN AND ASSESSMENT PRINCIPLES OF MANDARIN TEXTBOOKS}

\subsection{Assessment Principles of Textbooks}

Mandarin teaching materials in different areas have different characteristics as well as some common essence. Principles of textbooks compiling and of textbook evaluation are in consistence with each other, which are universally applicable for all kinds of materials, and should be followed. These principles can be summarized as: practical, intellectual, scientific and interesting.

\subsubsection{Practical}

Textbooks should fully embody the guiding function of theory to pronunciation, achieving pronunciation improvement in a certain period of time through some effort and inspiring the enthusiasm of the learners. Being practical implies practical teaching contents and practical teaching methods. Teaching content designed to meet the needs of the students and effective teaching methods will makes language learning easier.

\subsubsection{Intellectual}

New knowledge should be included in teaching content, of which the phonetic part is new to the learners. In addition, the quantity of drills is also a sign of being intellectual

\subsubsection{Scientific}

By scientific it means the theory should be normative, the explanation should be scientific and organization of teaching content should be complied with teaching rules. As to the place of articulation of a sound and the articulation method, the generally recognized rules and methods at present academic circles should be accepted. Meanwhile, sound recognition exercises should be in accordance with the teaching rules.

\subsubsection{Interesting}

Any kind of language learning and training is always accompanied with tedious exercises. Therefore, an interesting textbook can arouse the enthusiasm, interest and motivation of the learners, making the learning process interesting and happy. By interesting it means interesting teaching content and varying teaching methods.

\subsection{Basic Principles of Mandarin Teaching in Classroom}

\subsubsection{Clear Explanation by Teachers and Good Grasp by Students}

The most basic requirement for Mandarin course is to find out problems such as problems of phonetic knowledge, pronouncing method, error correction method and so on and to let students realize their problems and solve them.

\subsubsection{Explanation for common problems and no neglect of specific problems}

Clear explanation must be made to common problems in student's study and attention should be paid to some specific problems. Collective teaching and personal guidance, and mutual learning and group discussion should be combined.

\subsubsection{Teach a man to fish rather than give him fish}

People even from the same dialect area don't have identical problems and mandarin teaching materials may not be suitable for everyone. So, let the students find out their own mistakes and defects is the first step in Mandarin teaching, and how to teach the students according to their own questions to find out their own way to practice step by step is the work of the teachers.

\section{TEXTBOOK COMPILATION STRATEGIES AND SUGGESTIONS}

\subsection{Guided by function and focus on Practicality}

University Mandarin courses are not only for examination but also for improvement in their speaking and reading in Mandarin and for enhancing their personal images. Therefore, we propose to replace the "Gang" of the past with "function" as the 
outline and textbooks compilation revolves around two aspects: reading and speaking, in order to realize the aim of improvement in ability. This requires us to break with the past linear arrangement of "sound recognition - reading -talking. Reading and speaking cannot do without sound recognition and sound recognition should always be involved into reading and speaking, with practicality as the priority. Through mandarin study, students can master relatively standard discourse. For example, in each unit there is a discourse and explanations to some sound knowledge, reading and speaking skills are made, which is a thorough breaking with the past textbook system.

\subsection{Word-sentence as the basic unit}

Most textbooks are based on pronunciation (syllables), with the initial consonant, vowel, and tone practice around a single syllable, double syllables or three or four syllables. Due to the fact that syllables in language flow will be influenced by adjacent syllables, single syllables are prone to be pronounced wrongly in a phrase, especially in dynamic sentences. Based on this, the practice should adopt the way from "single syllable by syllable" as a starting point, to "sentence" as the end point. And a single syllable which is practiced in a sentence cannot be considered as understood thoroughly by the students. Thus, if a "text" is taken as the unit, and that syllables related to this unit are collected for practice, and these syllables are put into sentences for practice, accuracy of sentence reading can be ensured.

\section{3 "Tone - vowel - consonant" order}

Wang Qunsheng (1995), Xing Fuyi (2005) and Xing Hanguo (2008) have pointed out, "the tone is the most significant feature of Putonghua and Chinese dialects, which determines their pronunciation", and "the tone can determine a person's Mandarin level." And compared with the consonants and vowels, the tone is the most difficult part in our language study. We believe that in the process of learning Mandarin, the tone practice should be arranged before that of the consonants and vowels with more attention and exercises.

Vowels, although only including 10 vowels and two nasal consonants, are more complicated in composition when compared with consonants. They consist of single vowels, compound vowels and nasal vowels, which relate to the accuracy of mono-vowels pronunciation as well as changes of the tongue position in the oral cavity and the circular shape of the lips. At the same time, vowels will affect the whole syllable's saturation and pitch of the whole syllables and are the last part of a syllable. If the vowels are handled well, it will make the whole syllable sounded well. So, vowel practice arrangement should be earlier than that of the initial consonants.

\subsection{Specific advice for practice}

Emphasis will be laid on some pronunciations which are easy to be read wrongly and more exercises will be followed. In fact, it is not always impossible for a learner to pronounce a consonant or vowel, but difficult for him when a sound is combined with some sounds, so we should correct some mistakes step by step. For example, some people can't make a middle nasal sound $\mathrm{n}$, but after a period of practice they will make it.

\subsection{Teaching at different stages}

Two levels of practice in discourse exercises should be designed: primary and intermediate. In The Putonghua Training and Testing Guide compiled by Yunnan Province Language Committee a preliminary attempt has been made. According to the specific regional dialect, it is easier to for the mandarin teaching materials to be scientifically differentiated, because the hierarchical work needs further investigation. ------------------ Therefore, dental and retroflex exercises should be designed for primary level for students in northern dialect area while intermediate level for students in southern dialect areas.

\section{CONCLUSION}

The suggestions mentioned above are based on our study on many national mandarin textbooks, combined with the evaluation principles and their own teaching experience. For the time limit and too many textbooks for study, we just come to a crude conclusion. Due to the limitation in the writer's perspective and standpoint, the conclusion is inevitably with certain subjectivity, and quantitative research analysis of data and the discussion on the problems and further investigation are still necessary. As for how to design the exercises, how to carry out the hierarchical teaching, and how to carry out "word sentence"

\section{REFERENCES}

[1] Q.S. Wang .1996.Mandarin Tone Center method. Inner Mongolia people's Press: Wulumuqi.

[2] H.G.Xing.2008.Mandarin Proficiency Testing and Eloquence Improving, Jinan University Press: Guangzhou

[3] F.Y.Xing. Tutorial of Mandarin testing.2005.Hubei Science and Technology Press: Wuhan.

[4] F.Sun.2011. Putonghua training and testing, Shandong Education Press: Jinan. 